\title{
Key BIM Adoption Drivers to Improve Performance of Infrastructure Projects in the Ethiopian Construction Sector: A Structural Equation Modeling Approach
}

\author{
Solomon Belay $\mathbb{D D}^{1}{ }^{1}$ James Goedert, ${ }^{2}$ Asregedew Woldesenbet, ${ }^{1}$ Saeed Rokooei $\left(\mathbb{D},{ }^{3}\right.$ \\ José Matos, ${ }^{4}$ and Hélder Sousa $\mathbb{D}^{4}{ }^{4}$ \\ ${ }^{1}$ Faculty of Civil and Water Resources Engineering, Bahir Dar University, Bahir Dar, Ethiopia \\ ${ }^{2}$ The Durham School of Architectural Engineering and Construction, University of Nebraska-Lincoln, The Peter Kiewit Institute, \\ 1110 S 67th St., Omaha, NE 68182-0816, USA \\ ${ }^{3}$ College of Architecture, Art, and Design, Mississippi State University, 123 - D Howell Building, Starkville, MS 39759, USA \\ ${ }^{4}$ Department of Civil Engineering, University of Minho, Guimaraes, Portugal
}

Correspondence should be addressed to Solomon Belay; solomon.melaku@bdu.edu.et

Received 11 May 2021; Revised 10 September 2021; Accepted 16 September 2021; Published 24 September 2021

Academic Editor: Nicholas Chileshe

Copyright (c) 2021 Solomon Belay et al. This is an open access article distributed under the Creative Commons Attribution License, which permits unrestricted use, distribution, and reproduction in any medium, provided the original work is properly cited.

\begin{abstract}
The aim of this paper is to explore the critical BIM adoption drivers across the Ethiopian public infrastructure construction sector. In this regard, a comprehensive systematic literature review was employed to identify potential BIM implementation attributes in developing countries and validated through a pilot test. Then, quantitative data was collected from experts working in various organizations using a structured questionnaire survey. A structural equation model was then developed based on five key BIM adoption constructs and 14 adoption drivers. Based on the path analysis, Application, Environment, and Project related factors positively affect BIM adoption in infrastructure projects, whereas Organization and Information Management are insignificant and negatively affect BIM adoption in the Ethiopian construction industry. The study highlighted key BIM adoption attributes that are helpful to enhance the overall project management performance in infrastructure projects. The proposed action plan is beneficial to various professionals, government, and stakeholders in an effort to improve the current level of BIM uptake in the horn of Africa. More so, the findings of this paper can be used to facilitate and promote BIM adoption in public infrastructure construction projects across the Ethiopian construction market.
\end{abstract}

\section{Introduction}

Amidst the current global construction trend, the topic of integrating information technology (IT) and innovations in construction projects has been the center focus of governments and professionals in emerging markets $[1,2]$. These technological innovations are able to improve collaboration among stakeholders and enhance the overall project management of construction projects [3, 4]. Recently, the adoption of building information modeling into developmental infrastructure projects gains a widespread acceptance throughout the world [5].
Building information modeling, also known as BIM, presents ample benefits for practitioners and key stakeholders in the construction industry which invariably lead to improvements in project management efficiency and client satisfaction [6]. Developed nations such as the United States, United Kingdom, Australia, Hong Kong, and the majority of European countries are considered to be the pioneers of BIM implementation and integration in infrastructure projects [7]. These countries utilize BIM in several aspects of the project life cycle and enjoyed the wide range of implementing BIM in construction projects [8]. These benefits include better and effective design, clash detection, asset 
(facility) management benefits, effective scheduling and material delivery, improved communication and collaboration between parties, better rate of investment, and increased productivity [9-11].

In contrast, the adoption of BIM in developing nations have been slow due to various challenges. A number of research publications have emerged to address the extent of BIM implementation in various infrastructure construction projects. For instance, recent studies conducted in Nigeria [12], Pakistan [13], Malaysia [14], Armenia [15], Bangladesh [16], and Saudi Arabia [17] reported a low BIM uptake in developmental construction projects and recommended having collaborative efforts by the regulatory body, policy makers, and major stakeholders.

Prior studies reported various challenges that tend to hinder the wider BIM implementation and diffusion in construction projects [18-20]. These adoption challenges range from lack of financial and organizational resources, unavailability of skilled personnel, and poor collaboration among stakeholders. However, these studies fail to provide a critical analysis of BIM adoption drivers and attributes in public infrastructure projects, especially in emerging markets such as Ethiopia. There is also a gap in the literature regarding BIM adoption in developmental infrastructure projects across developing countries.

Hence, the purpose of this study is to examine the key drivers and strategies that affect the successful implementation of BIM in infrastructure construction projects across the Ethiopian construction sector. The study systematically explores the relationship between critical BIM implementation attributes using structural equation modeling. In addition, the paper proposes an action plan to enhance the overall BIM implementation and diffusion in public construction projects. The findings provide comprehensive BIM adoption strategies to public infrastructure projects for the Ethiopian construction industry, which will be helpful to professionals, government officials, policy makers, and other major stakeholders to improve BIM adoption in construction projects. Moreover, the study contributes to researchers in developing countries introducing structural equation modeling in studies related to BIM adoption strategies.

\section{Background of the Research Problem}

Infrastructure construction is considered as a key ingredient to foster growth and development in developing markets [21]. These infrastructure projects include road, transport, energy, and water works. In recent years, infrastructure projects have become complex and require huge financial, technological, machinery, and man power resources. Developing countries in particular have limited resources and are associated with low infrastructure development and poor urbanization [22].

Ethiopia, being one of the fastest growing economies in Africa, allocates $58-60 \%$ of the country's annual budget to infrastructure development during both the first and the second growth and transformation plans, also known as GTP I and II [23]. These strategies and actions have led the construction industry to grow intuitively and help to create job opportunities to millions of people throughout the country. Recent reports indicate that the growth of the construction sector has contributed approximately $5.6 \%$ to the country's overall GDP [24].

This development leads to the construction of big budgeted and complex infrastructure projects in major cities which in turn attracts some of the biggest contractors abroad $[23,25]$. The involvement of these foreign construction firms creates a great deal of competitions in developmental projects, introduces new technologies and construction techniques, and allows for local construction organizations to improve their own organizational structure and competency [26].

Having seen the recent information technology developments and integration to the construction sector around the globe, the Ethiopian government understood the need for a major change in the current practices of the Ethiopian construction industry to cope up with these advancements. In this respect, the Ethiopian government has introduced the concept of collaboration and capacity building schemes to advocate integration of major stakeholders and improve the overall project management performance of developmental infrastructure construction projects [27]. In this regard, the Ethiopian Ministry of Construction along with the Ethiopian Construction Project Management Institute launched a 5year strategic plan in 2017 to implement building information modeling (BIM) in public infrastructure projects. Since then, the regulatory body has been encouraging the adoption of BIM in different stages of the project life cycle [28].

However, despite the booming economy and the government's initiative to implement BIM in the infrastructure construction sector, the readiness of professionals and organizations is still low and several challenges including poor project management efficiency, low productivity, cost overrun, delays, and disputes among major stakeholders tend to hinder the wide range of BIM diffusion in construction projects [29]. To overcome these problems, a comprehensive BIM implementation strategy, along with the key BIM adoption drivers, has to be studied in the current construction setting. This strategy in turn will be helpful to enhance the level of BIM uptake and improve the project management performance of infrastructure projects in the Ethiopian construction industry.

In this regard, the present study aims to investigate the critical BIM adoption strategies in the context of the Ethiopian public infrastructure sector. Moreover, the paper utilizes a comprehensive systematic literature review in major databases to preselect BIM adoption drivers across emerging markets and utilizes a structural equation modeling to examine the relationship of key BIM attributes in line with infrastructure development. The study is believed to fill the gap of a limited literature that focus on BIM adoption and diffusion in infrastructure projects in the subSaharan African region.

\section{Literature Review}

BIM adoption has been the center focus of recent studies and generally considered as a technological innovation that 
promises to improve the overall performance of construction projects in the AEC industry $[10,15]$. The BIM process is identified as the force driving construction industries worldwide, and differences in national construction policy schemes in several nations correspondingly lead to variations in the development of BIM implementation strategies $[30,31]$.

BIM implementation is an emerging topic currently being investigated in various markets around the globe [32]. These studies cover different aspects of BIM adoption using country- and project-specific cases. For instance, Kiani et al. [19] explored the potential of BIM adoption in scheduling and planning phases in Iran. Ghazaryan [15] investigated the uniqueness of BIM implementation in the Armenian construction industry. A more comprehensive analysis of BIM adoption strategies in various Asian developing countries was published by [33]. The analysis reveals that although there is a low level of BIM adoption in those countries, there are potentials to improve the overall BIM uptake in developing countries.

Although prior studies adopted different techniques to provide empirical findings regarding BIM adoption strategies in the construction industry [34-36], there is still a dearth of systematic research regarding the key BIM adoption drivers particularly designed for the execution of infrastructure construction projects within the context of emerging markets, such as Ethiopia.

3.1. Systematic Literature Review (SLR). This study adopted a systematic literature review (SLR) to identify and summarize relevant high-quality publications regarding the potential BIM adoption drives in public infrastructure projects [37]. The studies of this SLR help to investigate the BIM implementation strategies in the Ethiopian construction industry.

The SLR process begin with a formulation of research questions and hypothesis, followed by selection of major databases and analysis of studies selected using certain criterion. These criterions include publication year, location, country, and methodology used. The present study explored whether the BIM adoption drivers in other developing countries can be contextualized in Ethiopia and then examined these preselected drivers using a questionnaire survey from various experts including client, consultant, contractors, and academia.

3.2. Inclusion and Exclusion Criteria. Inclusion and exclusion criterions are used to stipulate the studies to be included in the analysis and exclude studies that are irrelevant to the formulated hypothesis [38]. These criterions are predefined to specify the studies to be included in SLR and to make sure that relevant publications are used in an SLR and other irrelevant studies are omitted. The research articles from reputable peer reviewed journals and conferences were selected for review. For the current study, different inclusion/ exclusion criteria were used, which include language, methods applied, geographical location, research design, and publication year. These inclusion/exclusion criterions are in line with the inclusion and exclusion criteria used by [38-40].

Using the predefined criterions, the present study conducted the SLR process in the biggest databases such as Scopus, American Society of Civil Engineers (ASCE), Taylor and Francis Online, and Google Scholar. The terms and keywords such as "BIM Adoption in Public Projects", "Key BIM Adoption Drivers", "BIM Adoption in Developing Countries", and "Critical Success Factors of BIM Implementation in Infrastructure Projects" were applied in the search process. The review covers the range of publications in the period between 2011 and 2020.

During the initial search, a total of 117 papers from Scopus, 44 from ASCE, 87 from Taylor and Francis, and 214 from Google Scholar were returned. From this, duplicated publications were discarded and 364 papers were filtered for further scrutiny. Then, a full-text evaluation was conducted based on the inclusion/exclusion criterions listed above; this stage resulted in 44 papers. From this, 11 publications were further short listed for the questionnaire development considering studies conducted in public infrastructure projects in developing countries, and the remaining 33 studies were used for analysis and discussion throughout the paper (Table 1).

\section{Research Design}

The purpose of this study is to investigate the critical BIM adoption strategies that focus on public construction projects in developing countries. The empirical data was collected from professionals working in the Ethiopian construction sector and analyzed through structural equation modeling (SEM) (Table 2).

4.1. Reasons for Using Structural Equation Modeling. SEM is a sophisticated and multivariate statistical approach, which is popular in different academic fields, ranging from social and natural science fields [47]. Recently, SEM is becoming prevalent in the field of construction engineering and management. The popularity of SEM in BIM adoption studies is linked to the fact that SEM allows for the analysis of direct and indirect impacts of latent constructs between exogenous and endogenous variables [48]. In addition, SEM is an important statistical analysis tool which helps to examine the correlation (relationship) between observed and measured factors using a path diagram $[2,36]$.

4.2. Model Hypothesis. Based on the systematic literature review, the structural model of the study consists of 5 BIM attributes (Organization, Application, Environment, Information, and Project) and 14 factors/variables affecting BIM adoption in construction projects. These BIM attributes define the construction project-specific environment and were selected from past studies (see the systematic literature review section) taking into account the adequacy and reliability of these drivers and factors against the current setting of the Ethiopian construction industry. Consequently, a total of five hypotheses were formulated through a structural 
TABLE 1: Summary of the selected papers for the current study.

\begin{tabular}{|c|c|c|c|c|}
\hline No. & Author & Topic & Method & Country \\
\hline 1 & {$[30]$} & $\begin{array}{c}\text { Comparative analysis of drivers to BIM adoption among AEC firms in developing } \\
\text { countries: a case of Nigeria }\end{array}$ & Factor analysis & Nigeria \\
\hline 2 & [17] & $\begin{array}{c}\text { Evaluation of the Saudi construction industry for adoption of building information } \\
\text { modeling }\end{array}$ & Descriptive statistics & $\begin{array}{l}\text { Saudi } \\
\text { Arabia }\end{array}$ \\
\hline 3 & {$[37]$} & $\begin{array}{c}\text { Recent developments of BIM adoption based on categorization, identification, and } \\
\text { factors: a systematic literature review }\end{array}$ & $\begin{array}{l}\text { Systematic literature } \\
\text { review }\end{array}$ & Malaysia \\
\hline 4 & [41] & $\begin{array}{c}\text { Critical strategies for enhancing BIM implementation in AEC projects: perspectives } \\
\text { from Chinese practitioners }\end{array}$ & Factor analysis & China \\
\hline 5 & {$[42]$} & $\begin{array}{l}\text { A structure equation model of indicators driving BIM adoption in the Bahraini } \\
\text { construction industry }\end{array}$ & SEM & Bahrain \\
\hline 6 & [20] & Barriers to BIM implementation strategies in China & Descriptive stati & China \\
\hline 7 & {$[43]$} & $\begin{array}{c}\text { Organizational change perspective on people management in BIM implementation in } \\
\text { building projects }\end{array}$ & Factor analysis & Sing \\
\hline 8 & [44] & Critical success factors of building ir & ANOVA & Turkey \\
\hline 9 & {$[6]$} & $\begin{array}{c}\text { Confirmatory strategic information technology implementation for building } \\
\text { information modeling adoption model }\end{array}$ & SEM & Malaysia \\
\hline 10 & {$[45]$} & $\begin{array}{c}\text { Developing critical success factors for the assessment of BIM technology adoption: } \\
\text { part I. Methodology and survey }\end{array}$ & Descriptive statistics & Taiwan \\
\hline 11 & {$[46]$} & The benefits, obstacles, and problems of practical BIM implementation & Content analysis & Lithuania \\
\hline
\end{tabular}

TABLe 2: BIM implementation drivers adopted from the SLR.

\begin{tabular}{lcc}
\hline Attributes & Code & Factors \\
Organization & B1 & Adequate IT infrastructure \\
& B2 & Availability of financial resources \\
Effective senior leadership
\end{tabular}

equation modeling (Figure 1). These hypotheses include the following:

Organization: This is the first BIM attribute that affects BIM implementation in infrastructure construction projects. This BIM adoption driver focuses on factors such as adequate IT infrastructure, availability of financial resources, and effective senior leadership.

$\mathrm{H}_{1}$ : Organization has a positive impact on BIM adoption in the Ethiopian construction sector.

Application: the second BIM adoption attribute selected through the SLR is Application. Application focuses on the technical and cooperative aspects of BIM implementation in project-specific cases. The factors that influence the Application driver are availability of technical support for employees, collaborative working environment in firms, government policy, and availability of quality control and specifications.
$\mathrm{H}_{2}$ : Application affects BIM adoption in the Ethiopian construction sector.

Environment: this attribute takes into account the external environmental factors that affect the adoption of BIM in public construction projects. These factors include appropriate legal parameters, standards and guidelines for BIM adoption, and competent consultancy service.

$\mathrm{H}_{3}$ : Environment has a positive impact on BIM adoption in the Ethiopian construction sector.

Information Management: the $4^{\text {th }}$ BIM attribute considered after the SLR is Information Management. This factor is comprised of two distinct factors: sufficient model interoperability data and regular communication between stakeholders.

$\mathrm{H}_{4}$ : Information Management affects BIM adoption positively in the Ethiopian construction sector. 


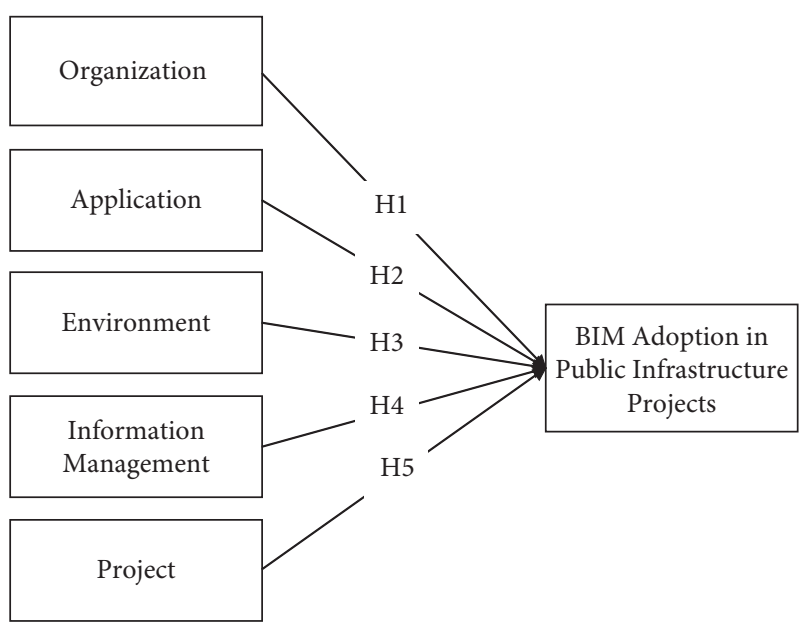

Figure 1: SEM model hypothesis used in this study.

Project: the final driver that affects BIM adoption in public infrastructure sector is Project. This driver/attribute takes into account factors such as appropriate choice of delivery and contract types, and risks associated with BIM.

$\mathrm{H}_{5}$ : Project has a positive impact on BIM adoption in the Ethiopian construction sector.

4.3. Data Collection. The current study adopted a two-stage data collection technique. The first stage of the data collection was based on a pilot study consisting of 12 experts working in various construction projects in and around the city of Bahir Dar. The pilot study was conducted as a pretest of the draft questionnaire for the purpose of checking overall language usage, assessing the average time needed to fill out the questions, and checking the compatibility of statistical tools against the questionnaire format for the main data collection (second stage) and analysis.

A 5-point Likert scale, ranging from $1=$ not critical, $2=$ not quite critical, $3=$ fairly critical, $4=$ very critical, and $5=$ extremely critical, was adopted in this study to get the perception of professionals who consisted of clients, consultants, contractors, and academia and are currently working in public construction projects across Ethiopia. Prior studies suggest that a 5-point Likert scale has been proven to be useful for a reliable data analysis in similar investigations around the world $[41,44]$.

The draft questionnaire then was sent to four experienced professionals ( 2 in academia and 2 in the industry) for content validation. The content validation helps to validate certain BIM adoption strategies taken from the literature against the cultural and other related factors and the overall language usage in the questionnaire.

4.4. Respondents Profile. After the completion of the pilot test, the revised questionnaire was then sent out to 181 experts in the field of architecture, civil engineering, and construction using face to face meetings and emails. The study adopted a purposive sampling technique to draw reliable data from professionals with a good BIM knowledge working in various organizations across the Ethiopian public construction sector. A total of 110 questionnaires were filled and returned back, which implies a $61 \%$ overall response rate. From these, after discarding incomplete questionnaires, 96 valid responses were taken for further analysis. In order to enhance the validity and reliability of responses, experts who has a 5-year or more professional experience in public construction projects in the Ethiopian construction sector were considered for the study.

The sample size is considered to be adequate when compared with previous studies published in the topic of BIM adoption. For instance, [44] used 96 samples, [49] used 100 samples, and [43] used 84 samples. Moreover, according to [41], factor analysis and/or SEM requires a sample size of at least five times the number of factors used in this study. In this case, the ratio is computed as $96 / 14=6.86$, which is satisfactory. Table 3 describes the demographic profile of participants.

\section{Analysis and Findings}

This section covers the analysis and findings in both measurement and structural SEM models developed to explore the potential BIM implementation strategies in the Ethiopian construction sector.

5.1. Measurement Model: Confirmatory Factor Analysis. A measurement model in SEM indicates the relationship between latent factors and a set of observed factors within certain distinct endogenous variables [49]. A confirmatory factor analysis (CFA) was conducted to check the model fit of values.

5.2. Model Fit. The model fit of the measurement model for public infrastructure construction projects was computed against common measure indexes such as normed chi square (CMIN/DF), root mean square residual (RMR), comparative fit index (CFI), and root mean square error of approximation (RMSEA). The cutoff fitness ranging values are summarized in Table 4.

The empirical data collected through a structured questionnaire survey were analyzed using a statistical software package IBM ${ }^{\circledast}$ SPSS $^{\circledR}$ AMOS 23. Prior studies also recommended IBM $^{\circledast}$ SPSS $^{\circledast}$ AMOS to accurately model the relationship among endogenous and exogenous variables while implementing SEM [2, 42, 47]. The measurement model was iterated eleven times before achieving model fit values of $\mathrm{CMIN} / \mathrm{DF}=1.411, \mathrm{RMR}=0.074, \mathrm{CFI}=0.962$, and $\mathrm{RMSEA}=0.066$. The model fit indices result reveals that all model fit measures satisfy the acceptable ranges provided in Table 4 . Hence, it can be concluded that the measurement model achieves a very good fit.

5.3. Reliability and Validity. The reliability of the measurement model was tested using indicators such as Cronbach's alpha $(\alpha)$, squared multiple correlation (SMC), 
TABle 3: Demography of experts.

\begin{tabular}{|c|c|c|}
\hline Profile & Frequency & Percentage (\%) \\
\hline \multicolumn{3}{|c|}{ Experience (years) } \\
\hline $6-10$ & 52 & 54 \\
\hline $11-15$ & 34 & 35.5 \\
\hline$>15$ & 10 & 10.5 \\
\hline \multicolumn{3}{|c|}{ Organization (firm) } \\
\hline Client & 13 & 13.5 \\
\hline Consultant & 41 & 43 \\
\hline Contractor & 27 & 28 \\
\hline Academia & 15 & 15.5 \\
\hline
\end{tabular}

TABLE 4: Summary of goodness-of-fit cutoff values (source: [32].

\begin{tabular}{lcc}
\hline Measure & Code & Acceptable range \\
\hline Normed chi square & CMIN/DF & $1-3$ \\
Root mean square residual & RMR & $<0.1$ \\
Comparative fit index & CFI & $>0.8$ \\
Root mean square error of approximation (RMSEA) & RMSEA & $<0.1$ \\
\hline
\end{tabular}

composite reliability (CR), and average variance extracted (AVE).

Cronbach's alpha $(\alpha)$ tests the internal consistency of an instrument. The minimum acceptable value of $\alpha$ is 0.7 . The threshold value of this indicator for a reliable internally consistent model is 0.70 or higher. Cronbach's alpha of the five BIM attributes used in the current study have all exceeded the minimum threshold by scoring between 0.731 and 0.898 (Table 5). Hence, the analysis confirms the reliability of the measurement model.

Similarly, the minimum threshold value for SMC $\left(R^{2}\right)$ of the observed indicators is 0.30 , and values exceeding 0.50 denote good reliability [8]. For the current study, the computed SMC values for the all BIM adoption drivers range between 0.378 and 0.982 , which proves the reliability of the indicators.

With regard to average variance extracted (AVE), values exceeding 0.5 are considered to be reliable (Table 6). The SEM analysis reveals that the AVE values for Organization, Application, Environment, Information Management, Project, and Process are $0.674,0.519,0.531,0.735$, and 0.727 , respectively. All these values exceed the minimum threshold of 0.5 , and the data fulfills the requirement.

Moreover, construct reliability (CR) was used to test the reliability of the data by measuring the level of Coefficient $\mathrm{H}$. The acceptable minimum threshold of Coefficient $\mathrm{H}$ is 0.70. All the resulting $\mathrm{CR}$ values of the constructs have exceeded 0.70 indicating a high level of reliability. As shown in Table 5, the CR values are all above the cutoff of 0.70 . Thus, the data used in the study is reliable.

The validity of the measurement model is tested using convergent validity and discriminatory validity. The literature requires item loadings greater than 0.70 and average variance extracted (AVE) no less than 0.50 for convergent validity [2, 42]. In which case, the factor loadings of each BIM adoption attribute were greater than 0.70 and the AVE values were higher than 0.50 (Table 5). Consequently, the empirical data is considered to be valid.
More so, discriminant validity, also known as interconstruct correlation, was conducted to check the validity of the data. Discriminant validity entails higher AVE values of indicators than shared variances of each indicator with all the other drivers. Comparing the square roots of AVE values with the inter-construct correlations in Table 7 reveals that all correlations were lower than the corresponding square roots of AVEs, indicating sufficient discriminant validity (DV) was achieved.

All these tests together confirm that (1) the performed measurements to evaluate the constructs of the BIM adoption drivers are valid; and (2) the instruments used and the data collected are reliable. Therefore, it can be concluded that the validation of the proposed BIM adoption taxonomy was achieved.

5.4. Structural Model: Path Analysis. Path analysis, also known as structural equation modeling (SEM), covariance structural equation modeling (CSEM), or covariance structure analysis, is a causal model consisting of several variables that helps to explore the relationship within a defined network [2]. In the current study, path analysis is conducted to test the statistical significance of exogenous variables (Organization, Application, Environment, Information Management, and Project) on the independent variable (BIM adoption in infrastructure projects) as shown in Figure 2.

Hypothesis testing for BIM adoption attributes is presented in Table 8. The effect of Organization related factors $\left(\mathrm{H}_{1}\right)$ on BIM adoption was not significant $(P=0.533)$, confirming that Organization negatively affects the current BIM uptake in the Ethiopian construction sector. Therefore, $\mathrm{H}_{1}$ is rejected. Similarly, the path loading of Application $(P=0.026)$ shows that Application related factors affect BIM adoption in the Ethiopian public infrastructure sector. Hence, $\mathrm{H}_{2}$ is accepted.

Information Management was with a $P$-value of 0.44 . This means that Information Management negatively affects 
TABLE 5: Measurement model analysis summary for public infrastructure projects.

\begin{tabular}{|c|c|c|c|c|c|c|}
\hline BIM drivers & Items & Factor loading & S.M.C $\left(R^{2}\right)$ & C.R. & AVE & Cronbach's alpha \\
\hline \multirow{3}{*}{ Organization } & Q1 & 0.991 & 0.982 & \multirow{3}{*}{0.857} & \multirow{3}{*}{0.674} & \multirow{3}{*}{0.847} \\
\hline & Q2 & 0.801 & 0.641 & & & \\
\hline & Q3 & 0.632 & 0.400 & & & \\
\hline \multirow{4}{*}{ Application } & Q4 & 0.614 & 0.378 & \multirow{4}{*}{0.924} & \multirow{4}{*}{0.519} & \multirow{4}{*}{0.898} \\
\hline & Q5 & 0.870 & 0.757 & & & \\
\hline & Q6 & 0.970 & 0.941 & & & \\
\hline & Q7 & 0.898 & 0.806 & & & \\
\hline \multirow{3}{*}{ Environment } & Q8 & 0.760 & 0.578 & \multirow{3}{*}{0.772} & \multirow{3}{*}{$0.531^{\prime}$} & \multirow{3}{*}{0.781} \\
\hline & Q9 & 0.731 & 0.535 & & & \\
\hline & Q10 & 0.694 & 0.482 & & & \\
\hline \multirow{2}{*}{ Information management } & Q11 & 0.835 & 0.698 & \multirow{2}{*}{0.847} & \multirow{2}{*}{0.735} & \multirow{2}{*}{0.824} \\
\hline & Q12 & 0.879 & 0.772 & & & \\
\hline \multirow{2}{*}{ Project } & Q13 & 0.728 & 0.531 & \multirow{2}{*}{0.839} & \multirow{2}{*}{0.727} & \multirow{2}{*}{0.731} \\
\hline & Q14 & 0.961 & 0.924 & & & \\
\hline
\end{tabular}

S.M.C, square multiple correlation; CR, composite reliability; AVE, average variance extracted.

TABLE 6: Acceptable values for evaluation of model reliability (source: [32].

\begin{tabular}{lccc}
\hline No. & Reliability measures & Symbol & Acceptable range for SEM model reliability \\
\hline 1 & Internal consistency (Cronbach's alpha) & $\alpha$ & $>0.7$ \\
2 & Average variance extracted & AVE & $>0.5$ \\
3 & Composite reliability & CR & $>0.7$ \\
4 & Squared multiple correlation & SMC $\left(R^{2}\right)$ & $>0.5$ \\
\hline
\end{tabular}

TABLE 7: Interconstruct correlation (discriminant validity) for public infrastructure projects.

\begin{tabular}{|c|c|c|c|c|c|}
\hline Attributes & Organization & Application & Environment & Information Management & Project \\
\hline Organization & 0.821 & & & & \\
\hline Application & 0.106 & 0.720 & & & \\
\hline Environment & 0.038 & 0.071 & 0.729 & & \\
\hline Information Management & 0.155 & 0.121 & -0.010 & 0.857 & \\
\hline Project & 0.099 & 0.573 & 0.138 & -0.013 & 0.853 \\
\hline
\end{tabular}

The diagonal values are the square root of AVE values of each BIM adoption driver.

BIM adoption in Ethiopia, whereas in the case of the Environment related BIM adoption drivers, the path analysis result indicated that it is significant with a $P$-value of 0.049 . This means that the external environment positively affects BIM adoption in the Ethiopian infrastructure construction sector. In addition, the Project $\left(\mathrm{H}_{5}\right)$ attribute is found to be significant with a $P$-value of 0.031 . In which case, $\mathrm{H}_{5}$ is accepted.

\section{Discussion and Practical Implication}

The SEM analysis reveals that, from the five identified BIM attributes, three of the components were significant for BIM adoption in the Ethiopian construction industry. These valid components include Application, Environment, and Project. The remaining two components, Organization and Information Management, are insignificant to the adoption of $\mathrm{BIM}$ in infrastructure projects.
6.1. Component I: Application. In the context of developing countries, infrastructure projects are complex and draw a lot of attention to the public due to their importance [50]. These projects are often taking a huge budget and allow for the participation of several stakeholders within a single collaborative environment [51]. Hence, implementing BIM in infrastructure projects needs a comprehensive adoption framework and strategy in line with contractual obligations. In this study, Application is the first significant component that affects BIM implementation in the Ethiopian construction sector. This component is comprised of four factors including availability of technical support for employees, collaborative working environment in firms, government policy, and availability of quality control and specifications with factor loadings of $0.614,0.870$, 0.970 , and 0.898 , respectively. The result coincides with the findings of $[41,48,52]$.

The extent and availability of BIM engineers in the market have been one of the major challenges of BIM 


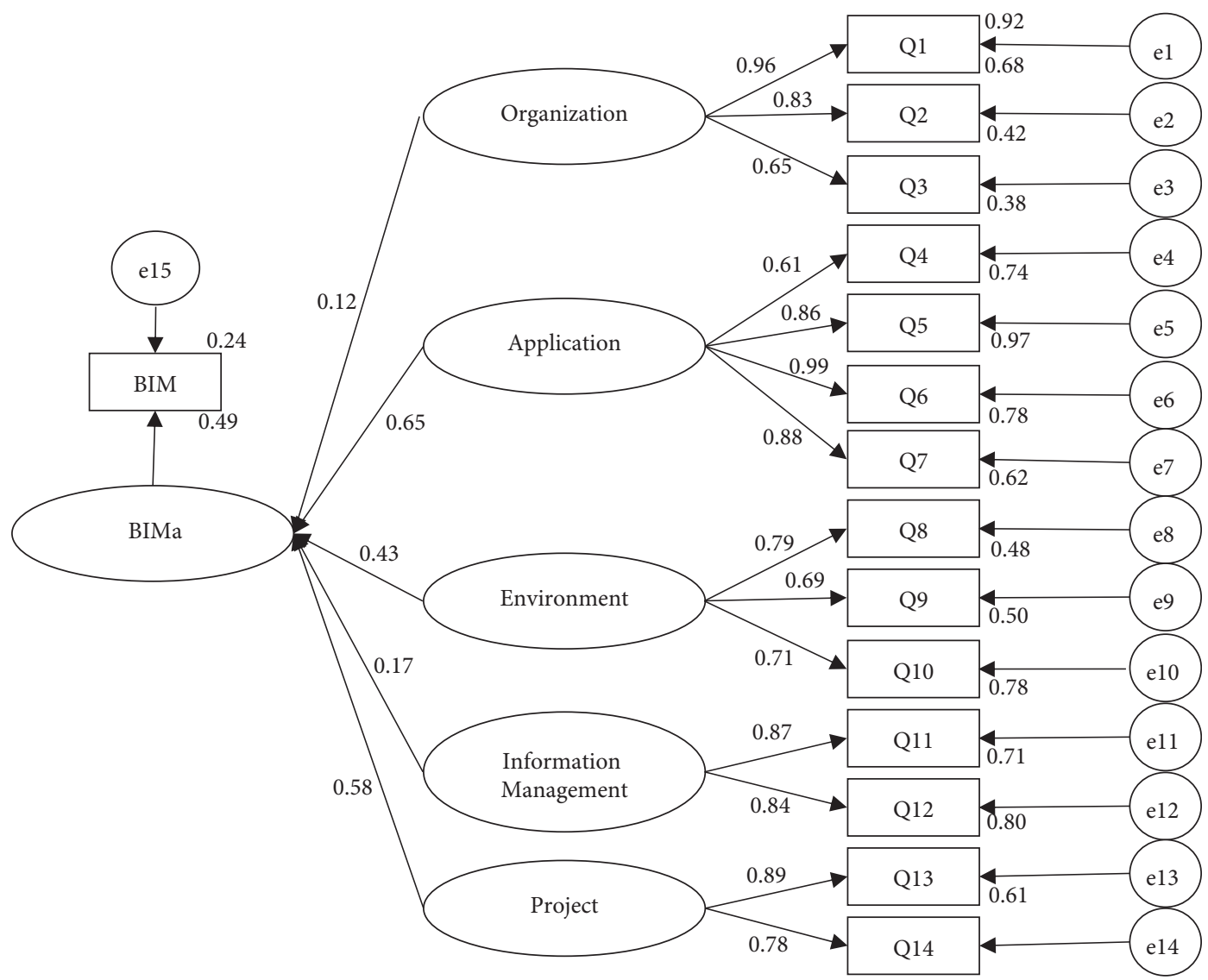

Figure 2: Structural model of the study.

TABLE 8: Summary of hypothesis testing results.

\begin{tabular}{lccc}
\hline Key BIM attributes & Hypothesis & $P$ value & Remark \\
\hline Organization & $\mathrm{H}_{1}$ & 0.533 & Reject \\
Application & $\mathrm{H}_{2}$ & 0.026 & Accept \\
Environment & $\mathrm{H}_{3}$ & 0.049 & Accept \\
Information Management & $\mathrm{H}_{4}$ & 0.44 & Reject \\
Project & $\mathrm{H}_{5}$ & 0.031 & Accept \\
\hline
\end{tabular}

N.B, estimates with $P$ values less than 0.05 are considered to be significant.

diffusion in emerging markets, particularly in the African continent [53]. For instance, the study by [34] in Nigeria reported that unavailability of skilled personnel in big construction companies and lack of training for professionals are the obstacles that hinder the adoption of BIM in the construction sector. Similarly, Rogers, Chong, and Preece (2015) addressed the criticality of technical competency of professionals in BIM enabled projects in Malaysia. The other BIM attributes in the Application component are collaborative working environment and government policy. These attributes are associated with delivery methods in construction contractual obligations $[4,54]$.

6.2. Component II: Environment. BIM enables a collaborative working platform which allows the professionals to exchange digital data and information across the project life cycle. Environment is the second significant component in the structural model. This component consists of three BIM adoption attributes: appropriate legal parameters, standards, and guidelines for BIM adoption, and competent consultancy service with factor loadings $0.760,0.731$, and 0.694, respectively. Prior studies reported that lack of standards and specifications is considered as the major hindrance of BIM implementation and diffusion in emerging markets $[53,55]$.

In Hong Kong, Olawumi and Chan [52] discussed the need for devising legal parameters for successful implementation of BIM in construction projects. In Malaysia, Enegbuma, Aliagha, and Ali [6] reported that the lack of comprehensive BIM related legal standards slowed BIM diffusion across the construction sector. Similarly, recent studies conducted in China, Taiwan, and Australia stressed the importance of a collaborative approach by stakeholders to have an open standard and guideline for BIM implementation in the construction industry [56-58]. In the perspective of the impact of technological innovations in construction projects, [59] reported the advancement of the UK construction sectors towards devising BIM standards for a successful BIM adoption and diffusion in building construction projects.

6.3. Component III: Project. The third statistically significant BIM adoption component is Project. This component consists of two major drivers. These include appropriate 
TABle 9: Action plan to improve BIM adoption across the Ethiopian infrastructure construction industry.

\begin{tabular}{|c|c|}
\hline Valid BIM adoption components & Proposed action plan to improve BIM adoption \\
\hline \multicolumn{2}{|l|}{ Component 1: Application } \\
\hline $\begin{array}{l}\text { Availability of technical support for } \\
\text { employees }\end{array}$ & $\begin{array}{l}\text { (i) CEOs and project managers shall allocate funds to provide continuous capacity building } \\
\text { trainings for their employees to improve BIM adoption in organizations } \\
\text { (ii) Business leaders shall revise the organization's overall structure in line with new technology } \\
\text { adoption, such as BIM }\end{array}$ \\
\hline $\begin{array}{l}\text { Collaborative working environment } \\
\text { in firms }\end{array}$ & $\begin{array}{l}\text { (i) Different contract and project delivery techniques need to be explored in projects } \\
\text { (ii) Provide various gatherings to improve the project team spirit } \\
\text { (iii) Plan continuous site meetings among stakeholders and professionals }\end{array}$ \\
\hline Government policy & $\begin{array}{l}\text { (i) Government should devise policy schemes and national strategies to improve BIM } \\
\text { implementation } \\
\text { (ii) Government should work closely with universities and academia to design courses and } \\
\text { enhance the awareness of professionals } \\
\text { (iii) The regulatory body and policy makers shall take the initiative to lead the adoption of BIM } \\
\text { across the construction sector }\end{array}$ \\
\hline $\begin{array}{l}\text { Availability of quality control and } \\
\text { specifications }\end{array}$ & $\begin{array}{l}\text { (i) There should be a national quality control and quality assurance strategy for BIM enabled } \\
\text { projects } \\
\text { (ii) Regulatory body should organize continuous meetings with stakeholders to make sure } \\
\text { stakeholders got what they need to successfully implement BIM } \\
\text { (iii) Stakeholders need to work and collaborate with universities and the government to have } \\
\text { appropriate standards and specifications for BIM enabled infrastructure projects }\end{array}$ \\
\hline
\end{tabular}

Component 2: Environment

Appropriate legal parameters

Standards and guidelines for BIM adoption

Competent consultancy service

Component 3: Project

Appropriate choice of delivery and contract types

Risks associated with BIM (i) Government along with key stakeholders shall take the initiative to devise suitable legal articles with respect to BIM usage in infrastructure projects

(i) Design appropriate BIM related standards and guidelines as per the Ethiopian construction setting

(ii) Engage with international companies and foreign governments to assist with open BIM standards

(i) Government should support local consulting firms in line with the BIM advancement

(ii) Universities should give continuous trainings to consultants

(i) Propose compatible delivery method with the implementation of BIM in projects (ii) Capacitate local construction firms to have their own design team in the organizational structure

(i) Engage with insurance companies and financers at every stage of the project life cycle

(ii) Conduct researches to improve BIM inclusion and usage along with the current contract document choice of delivery and contract types (factor loading $=0.728$ ), and risks associated with BIM (factor loading $=0.961)$. Prior studies agreed that BIM enabled projects should be able to adopt appropriate type of contracting methods to enhance project management in infrastructure projects [60]. [41] reported the importance of choosing the most appropriate contracting methods in BIM enabled projects to ensure success. Similarly, [60] studied the potential challenges and risks associated with BIM adoption in France. The authors identified different types of risks from external, internal, and cultural perspectives. More so, in Saudi Arabia and Bangladesh, risk factors such as high initial investment cost and unavailability of policies and insurances for risks that may arise from using BIM in construction projects affect the extent of BIM adoption and diffusion in the construction sector $[16,17]$.

6.4. Proposed Action: Plan to Improve BIM Adoption. After analyzing the data collected through a structure questionnaire survey, a BIM adoption framework is proposed to improve the overall BIM adoption and diffusion in infrastructure construction projects (Table 9). The action plan is based on the output developed from both the structural equation modeling analysis and a comprehensive literature review to provide a robust strategical output. The proposed action plan (recommendation) focuses on the collaborative efforts from all stakeholders across the construction industry.

The first section of the proposed action plan focuses on the application related BIM drivers. The proposed recommendations are forwarded to have an improved communication among key stakeholders and to have ample guidelines for successful BIM adoption in the Ethiopian construction sector. Secondly, the external environment related recommendations were proposed in relation to the impact of the overall construction system/process to the successful adoption of BIM in construction organizations.

The last section consists of the third component extracted from the analysis section, project related factors. In this case, the proposed action plan is forwarded in relation to the responsibility of government, regulatory body, 
universities, and other stakeholders to improve the current contract administration and minimize the risk of implementing BIM infrastructure construction projects.

\section{Conclusion}

Recently, BIM has been promoted by governments in developing countries through initiatives and schemes to encourage BIM implementation in the construction industry. The current study aimed to investigate the potential BIM adoption attributes/drivers in the Ethiopian construction sector based on structural equation modeling. The result indicates that indicators such as Application, Environment, and Project related factors positively affect BIM adoption in the Ethiopian public infrastructure sector, whereas Organization and Information Management negatively affect BIM adoption in infrastructure projects. In addition, based on the findings of the SEM analysis, key action plans and recommendations were forwarded to improve the current level of BIM uptake in the Ethiopian public infrastructure sector.

The major contribution of this study is twofold: (1) Ethiopia is currently in the Pre-BIM adoption stage with a huge potential and initiative by stakeholders to adopt and diffuse BIM in construction projects. In this case, the study for the first time contributes comprehensive BIM adoption strategies for the Ethiopian construction sector. (2) There is still a dearth of studies in developing nations, especially in east African region, related to BIM implementation strategies and drives in developmental infrastructure projects. Hence, the study can be used as a benchmark to promote BIM adoption researches/publications in the horn of Africa, and to the wider sub-Saharan African region.

The study has a few limitations. Firstly, the study does not differentiate infrastructure projects types (industrial, residential, water works) for the analysis, although prior studies also adopted similar generalized project types. Secondly, the proposed framework still needs a critical review of its applicability and soundness, despite the fact that the action plan is proposed based on firsthand empirical data in the infrastructure construction sector. Thirdly, quantitative technical approach was conducted during data collection. This method has been common in BIM adoption studies. However, qualitative analysis could have also provided additional data for the analysis. For future studies, researches could focus on using mixed data collection instruments to acquire sufficient data for analysis in BIM related studies; and investigation of BIM adoption drivers related to infrastructure projects with the involvement of government officials and regulatory body could be explored.

\section{Data Availability}

The data underlying the results presented in the study are available within the article.

\section{Conflicts of Interest}

The authors declare no conflicts of interest.

\section{References}

[1] Y. Al-Saeed, E. Parn, D. J. Edwards, and S. Scaysbrook, "A conceptual framework for utilising BIM digital objects (BDO) in manufacturing design and production," Journal of Engineering, Design and Technology, vol. 17, no. 5, pp. 960-984, 2019.

[2] G. Ngowtanasawan, "A causal model of BIM Adoption in the Thai architectural and engineering design industry," Procedia Engineering, vol. 180, pp. 793-803, 2017.

[3] T. O. Olawumi and D. W. M. Chan, "Building information modelling and project information management framework for construction projects," Journal of Civil Engineering and Management, vol. 25, no. 1, pp. 53-75, 2019.

[4] A. Porwal and K. N. Hewage, "Building Information Modeling (BIM) partnering framework for public construction projects," Automation in Construction, vol. 31, pp. 204-214, 2013.

[5] Y. Gamil and I. A. R. Rahman, "Awareness and challenges of building information modelling (BIM) implementation in the Yemen construction industry," Journal of Engineering, Design and Technology, vol. 17, no. 5, pp. 1077-1084, 2019.

[6] W. I. Enegbuma, fnm au, G. U. Aliagha, K. N. Ali, and Y. Y. Badiru, "Confirmatory strategic information technology implementation for building information modelling adoption model," Journal of Construction in Developing Countries, vol. 21, no. 2, pp. 113-129, 2016.

[7] R. Charef, H. Alaka, and S. Emmitt, "Beyond the third dimension of BIM: a systematic review of literature and assessment of professional views," Journal of Building Engineering, vol. 19, no. 2017, pp. 242-257, 2018.

[8] A. L. Ahmed and M. Kassem, "A unified BIM adoption taxonomy: conceptual development, empirical validation and application," Automation in Construction, vol. 96, no. August, pp. 103-127, 2018.

[9] D. Bryde, M. Broquetas, and J. M. Volm, "The project benefits of building information modelling (BIM)," International Journal of Project Management, vol. 31, no. 7, pp. 971-980, 2013.

[10] A. Ghaffarianhoseini, J. Tookey, A. Ghaffarianhoseini et al., "Building Information Modelling (BIM) uptake: clear benefits, understanding its implementation, risks and challenges," Renewable and Sustainable Energy Reviews, vol. 75, no. October, pp. 1046-1053, 2017.

[11] K. Ullah, I. Lill, and E. Witt, "An overview of BIM adoption in the construction industry: benefits and barriers," in Proceedings of the 10th Nordic Conference on Construction Economics and Organization, pp. 297-303, Tallin, Estonia, May 2019.

[12] F. Ezeokoli, P. Okoye, and E. Nkeleme, "Factors affecting the adaptability of Building Information Modelling (BIM) for construction projects in anambra state Nigeria," Journal of Scientific Research and Reports, vol. 11, no. 5, pp. 1-10, 2016.

[13] R. Masood, M. K. N. Kharal, and A. R. Nasir, "Is BIM adoption advantageous for construction industry of Pakistan?" Procedia Engineering in Proceedings of the Fourth International Symposium on Infrastructure Engineering in Developing Countries, vol. 77, pp. 229-238, Elsevier B.V., Karachi, Pakistan, December 2014.

[14] W. Imoudu Enegbuma, U. Godwin Aliagha, and K. Nita Ali, "Preliminary building information modelling adoption model in Malaysia," Construction Innovation, vol. 14, no. 4, pp. 408-432, 2014. 
[15] M. Ghazaryan, "Pecularities of BIM adoption in Armenia," E3S Web of Conferences, vol. 97, Article ID 01025, 2019.

[16] M. F. H. Rakib, S. Howlader, and M. Rahman, "Factors affecting the BIM adoption in the construction industry of Bangladesh," Goedert \& Meadati, vol. 2018, pp. 19-21, 2011, Available at: http://www.cuet.ac.bd.

[17] O. Aljobaly and A. Banawi, "Evaluation of the saudi construction industry for adoption of building information modelling," Advances in Intelligent Systems and Computing, Springer International Publishing, Switzerland, pp. 488-498, 2020.

[18] S. Girginkaya Akdag and U. Maqsood, "A roadmap for BIM adoption and implementation in developing countries: the Pakistan case," Archnet-IJAR: International Journal of Architectural Research, vol. 14, no. 1, pp. 112-132, 2019.

[19] I. Kiani, A. Nobahar, S. Ghomi, and A. Marsono, "Barriers to implementation of building information modeling in scheduling and planning phase in Iran," Australian Journal of Basic and Applied Sciences, vol. 9, pp. 91-97, 2015.

[20] Y. Zhou, Y. Yang, and J.-B. Yang, "Barriers to BIM implementation strategies in China," Engineering Construction and Architectural Management, vol. 26, no. 3, pp. 554-574, 2019.

[21] N. Kavishe and N. Chileshe, "Critical success factors in publicprivate partnerships (PPPs) on affordable housing schemes delivery in Tanzania," Journal of Facilities Management, vol. 17, no. 2, pp. 188-207, 2019.

[22] K. Dithebe, C. O. Aigbavboa, W. D. Thwala, and A. E. Oke, "Factor analysis of critical success factors for water infrastructure projects delivered under public-private partnerships," Journal of Financial Management of Property and Construction, vol. 24, no. 3, pp. 338-357, 2019.

[23] E. Sinesilassie, S. Tabish, and K. Jha, "Critical factors affecting schedule performance: a case of ethiopian public construction projects - engineers' perspective," Engineering Construction and Architectural Management, vol. 22, no. 1, pp. 91-107, 2017.

[24] G. Y. Debela, "Critical success factors (CSFs) of public-private partnership (PPP) road projects in Ethiopia," International Journal of Construction Management, vol. 0, pp. 1-12, 2019.

[25] A. Mekonnen, "Role of government in the ethiopian construction industry," in Proceedings of the 5th National Workshop of the ECoTMPA, Addis Ababa, September 2016.

[26] T. H. Zewdie, "The effectivness of project management processes on performance of construction projects: case study analysis in selected companies in Addis Ababa," Management, vol. 6, no. 6, pp. 203-212, 2016.

[27] T. Ayalew, Z. Dakhli, and Z. Lafhaj, "Assessment on performance and challenges of ethiopian construction industry," Journal of Architecture and Civil Engineering, vol. 2, no. 11, pp. 1-11, 2016.

[28] ECPMI, The Impact of Building Information Modeling in the Ethiopian Construction Industry, ECPMI, Addis Ababa, Ethiopia, 2018.

[29] D. G. Mengistu and G. Mahesh, "Dimensions for improvement of construction management practice in ethiopian construction industry," Journal of Engineering, Design and Technology, vol. 18, no. 1, pp. 21-39, 2019.

[30] S. O. Babatunde, D. Ekundayo, A. O. Adekunle, and W. Bello, "Comparative analysis of drivers to BIM adoption among AEC firms in developing countries," Journal of Engineering, Design and Technology, vol. 18, no. 6, pp. 1425-1447, 2020.

[31] W. N. S. W. Mohammad, M. R. Abdullah, S. Ismail, and R. Takim, "Building information modeling (BIM) adoption challenges for contractor's organisations in Malaysia," AIP Conference Proceedings, vol. 2016, Article ID 020148, 2018.

[32] S. Belay, G. James, W. Asregedew, and R. Saeed, "Comparison of BIM adoption models between public and private sectors through empirical investigation," Advances in Civil Engineering, vol. 2021, no. April, Article ID 5577654, 2021.

[33] N. A. A. Ismail, M. Chiozzi, and R. Drogemuller, "An overview of BIM uptake in asian developing countries," AIP Conference Proceedings, vol. 1903, no. 1, Article ID 080008, 2017.

[34] G. Amuda-Yusuf, "Critical success factors for building information modelling implementation," Construction Economics and Building, vol. 18, no. 3, pp. 55-73, 2018.

[35] N. Bui, C. Merschbrock, and B. E. Munkvold, "A review of building information modelling for construction in developing countries," Procedia Engineering, vol. 164, no. 1877, pp. 487-494, 2016.

[36] Y. Hong, A. Hammad, X. Zhong, and B. Wang, "Comparative modeling approach to capture the differences in BIM adoption decision-making process in Australia and China," Journal of Construction Engineering and Management, vol. 146, no. 2, pp. 1-15, 2020.

[37] H. M. Faisal Shehzad, R. Binti Ibrahim, A. F. Yusof, K. A. Mohamed khaidzir, S. Shawkat, and S. Ahmad, "Recent developments of BIM adoption based on categorization, identification and factors: a systematic literature review," International Journal of Construction Management, pp. 1-13, 2020.

[38] T. D. Oesterreich and F. Teuteberg, "Behind the scenes: understanding the socio-technical barriers to BIM adoption through the theoretical lens of information systems research," Technological Forecasting and Social Change, vol. 146, no. 2018, pp. 413-431, 2019.

[39] F. H. Abanda, C. Vidalakis, A. H. Oti, and J. H. M. Tah, “A critical analysis of building information modelling systems used in construction projects," Advances in Engineering Software, vol. 90, pp. 183-201, 2015.

[40] M. Oraee, M. R. Hosseini, D. J. Edwards, H. Li, E. Papadonikolaki, and D. Cao, "Collaboration barriers in BIM-based construction networks: a conceptual model," International Journal of Project Management, vol. 37, no. 6, pp. 839-854, 2019.

[41] X. Ma, A. Chan, Y. Li, and B. Zhang, "Critical strategies for enhancing BIM implementation in AEC projects: perspectives from Chinese practitioners," Journal of Construction Engineering and Management, vol. 146, no. 2, pp. 1-10, 2020.

[42] S. H. A. Ahmed and S. M. A. Suliman, "A structure equation model of indicators driving BIM adoption in the bahraini construction industry," Construction Innovation, vol. 20, no. 1, pp. 61-78, 2020.

[43] L. Liao and E. Ai Lin Teo, "Organizational change perspective on people management in BIM implementation in building projects," Journal of Management in Engineering, vol. 34, no. 3, Article ID 04018008, 2018.

[44] B. Ozorhon and U. Karahan, "Critical success factors of building information modeling implementation," Journal of Management in Engineering, vol. 33, no. 3, 2017.

[45] M. Mom, M.-H. Tsai, and S.-H. Hsieh, "Developing critical success factors for the assessment of BIM technology adoption: part II. analysis and results," Journal of the Chinese Institute of Engineers, vol. 37, no. 7, pp. 859-868, 2014.

[46] D. Migilinskas, V. Popov, V. Juocevicius, and L. Ustinovichius, "The benefits, obstacles and problems of 
practical BIM implementation," Procedia Engineering, vol. 57, pp. 767-774, 2013.

[47] N. A. Adillah Ismail, M. Maisham, Z. A. Mohd Zaki, R. R. R. Muhammad Rooshdi, and S. R. Sahamir, "The mediating effects of cost estimates reliability on BIM adoption: SEM model analysis," IOP Conference Series: Earth and Environmental Science, vol. 385, no. 1, Article ID 012070, 2019.

[48] C. Y. Chang, W. Pan, and R. Howard, "Impact of building information modeling implementation on the acceptance of integrated delivery systems: structural equation modeling analysis," Journal of Construction Engineering and Management, vol. 143, no. 8, pp. 1-10, 2017.

[49] Y. Chen, H. Dib, M. Shaurette, and R. Cox, "Structural equation model of building information modeling maturity," Engineering Construction and Architectural Management, vol. 142, no. 3, 2016

[50] A. M. Abdullahi, M. Abdullahi, and A. Hassan, "An assessment of the level of building information modelling (BIM) implementation in small and medium enterprises (SMEs) in the nigerian construction industry," in Proceedings of the National Engineering Conference 2018, Article ID 52900, Zaria, Nigeria, January 2018.

[51] E. G. Sinesilassie, S. Z. S. Tabish, and K. N. Jha, "Critical factors affecting cost performance: a case of ethiopian public construction projects," International Journal of Construction Management, vol. 18, no. 2, pp. 108-119, 2018.

[52] T. O. Olawumi and D. W. M. Chan, "Critical success factors for implementing building information modeling and sustainability practices in construction projects: a delphi survey," Sustainable Development, vol. 27, no. 4, pp. 587-602, 2019.

[53] O. Olanrewaju, N. Chileshe, B. Sunday, and M. Sandanayake, "Investigating the barriers to Building Information Modeling (BIM) implementation within the nigerian construction industry," Engineering Construction and Architectural Management, vol. 27, no. 10, pp. 2931-2958, 2020.

[54] B. M. Almashjary, A. Sani, and A. Razak, "Establishing key factors towards implementing integrated Building Information Modeling (BIM) in AEC industry: Malaysia," Journal of Building Performance, vol. 11, no. 1, pp. 117-126, 2020.

[55] R. Eadie, H. Odeyinka, M. Browne, and C. Mckeown, "An analysis of the drivers for adopting building information modeling," Journal of Information Technology in Construction, vol. 18, pp. 338-352, 2013.

[56] A. Chegu Badrinath and S. H. Hsieh, "Empirical approach to identify operational critical success factors for BIM projects," Journal of Construction Engineering and Management, vol. 145 , no. 3, 2019.

[57] C. M. Herr and T. Fischer, "BIM adoption across the Chinese AEC Industries: an extended BIM adoption model," Journal of Computational Design and Engineering, vol. 6, no. 2, pp. 173-178, 2019.

[58] B. Succar, "Building information modelling framework: a research and delivery foundation for industry stakeholders," Automation in Construction, vol. 18, no. 3, pp. 357-375, 2009.

[59] Y. Arayici, P. Coates, L. Koskela, M. Kagioglou, C. Usher, and K. O'Reilly, "Technology adoption in the BIM implementation for lean architectural practice," Automation in Construction, vol. 20, no. 2, pp. 189-195, 2011.

[60] E. Hochscheid and G. Halin, "A model to approach BIM adoption process and possible bim implementation failures," in Proceedings of the Creative Construction Conference 2018 Proceedings, M. J. S. Hajdu, Ed., pp. 257-264pp. 257-, Ljubljana, 2018. 